\title{
Prevalence and clinical significance of antikeratin antibodies and other serological markers in Lithuanian patients with rheumatoid arthritis
}

\author{
L Vasiliauskiene, A Wiik, M Høier-Madsen
}

\begin{abstract}
Objectives-To assess the clinical value of several serological markers in Lithuanian patients with rheumatoid arthritis (RA) compared with control patients with rheumatic disease and age matched healthy controls.

Methods-Serum samples from 96 patients with RA of approximately 8 years' duration, 90 rheumatic disease controls, and 37 healthy subjects were tested. Antikeratin antibody (AKA), antineutrophil cytoplasmic antibody (ANCA), and antinuclear antibody (ANA) titres were estimated by indirect immunofluorescence (IIF) and serum samples positive for ANA and ANCA were further studied by enzyme linked immunosorbent assay (ELISA). IgA and IgM rheumatoid factors (RF) were measured by ELISA.
\end{abstract}

Results-A positive AKA test was highly specific for RA (diagnostic specificity $97 \%$ ), being found in $44 \%$ of the patients. Although both RF tests had a higher sensitivity, they were less specific for RA. ANCA was detected in $33 \%$ of patients with RA but lacked diagnostic specificity. AKA and ANCA were associated with more erosive disease and the presence of extra-articular manifestations. Positivity for AKA, IgA RF, and ANCA was significantly associated with disease activity and worse functional capacity. However, in multiple regression analysis only positivity for AKA was significantly correlated with functional disability $(p=0.0001)$, evaluated by the Steinbrocker functional classification, and no single marker had any relation with radiological damage. Conclusion-Although AKA showed the highest disease specificity, all serological markers studied except ANA exhibited interesting associations with important clinical and paraclinical parameters of RA.

(Ann Rheum Dis 2001;60:459-466)

Autoimmunology,

Statens Serum

Institut, Copenhagen, Denmark

A Wiik

M Høier-Madsen

Correspondence to:

Dr A Wiik, Department of

Autoimmunology, Statens

Serum Institut, Artillerivej 5,

DK-2300 Copenhagen S,

Denmark

aw@ssi.dk

Accepted 17 November 2000
RA. To date, the diagnosis of RA has been based on the American College of Rheumatology (ACR) criteria, ${ }^{1}$ and RF are the only autoantibodies included among the classification criteria. Raised titres of immunoglobulin A rheumatoid factors (IgA RF) are detected in $65-86 \%$ of patients with RA, ${ }^{23}$ and immunoglobulin $M$ rheumatoid factors (IgM RF) are increased in $70-92 \%$ of patients. ${ }^{24}$ However, their diagnostic specificity for RA is poor since $\mathrm{RF}$ are also found in many other rheumatic and non-rheumatic diseases and sometimes in healthy subjects. ${ }^{45}$

In addition, antineutrophil cytoplasmic antibodies (ANCA) and antinuclear antibodies (ANA) have been described in patients with RA. The reported prevalence of ANCA in RA is variable, ranging from $16 \%$ to $74 \% .^{6-11}$ However, ANCA are not specific antibodies for RA since they have been reported to occur in many other rheumatic diseases and inflammatory disorders. ${ }^{67}$ ANA are not specific for RA either, and there is no clear cut off titre to distinguish between patients with RA, those with soft tissue rheumatism, and normal individuals. ${ }^{12}$

Antibodies of a more disease specific nature have also been found in the serum of patients with RA. Antiperinuclear factors (APF), which specifically stain the so called keratohyaline granules of the epithelium of the buccal mucosa by indirect immunofluorescence (IIF), were first described by Nienhuis and Mandema in $1964 .{ }^{13}$ Later, in 1979, Young et $a l^{14}$ described an increased occurrence of the so called antikeratin antibodies (AKA) in the serum of patients with RA which were identified by IIF on the stratum corneum of the epithelium of rat oesophagus. Subsequently, a number of authors have described IgG APF and AKA in advanced RA, ${ }^{15-22}$ in very early $\mathrm{RA}^{23}$ and even before onset of the disease. ${ }^{24}$ These antibodies are very specific for RA: they occur with a nosological sensitivity of $36-91 \%$ and a diagnostic specificity of $73-100 \%$, depending on the technique used and the way positivity is interpreted. ${ }^{25}$ It has recently been shown that AKA and APF correspond to identical, or at least largely overlapping, populations of autoantibodies which recognise filaggrin, ${ }^{26}$ and a considerable overlap has been reported by these autoantibodies with regard to diagnostic properties. ${ }^{27}$ Furthermore, using an enzyme linked immunosorbent assay (ELISA) with a cyclic citrullinated peptide as antigen, which is recognised by APF and AKA, ${ }^{28}$ these particular antibodies were found in the majority of patients with early RA, especially in those who later developed active erosive disease. ${ }^{29} 30$ 
Regardless of the increase in knowledge about these related antibodies, the exact clinical significance of AKA in RA and their relations with other serological markers have remained uncertain. The present investigation was undertaken to determine the prevalence and to estimate the clinical significance of AKA, ANA, ANCA, and RF in patients with RA compared with control patients with rheumatic disease and age matched healthy subjects from Lithuania. Interrelationships between AKA, other serological markers of RA, and several clinical and laboratory variables of the disease were also investigated. This work is the first study of this type to be performed in Lithuanian patients.

\section{Materials and methods}

PATIENTS AND SERUM SAMPLES

Serum samples were obtained from 186 consecutive patients admitted to the Rheumatology Department of Vilnius University Red Cross Hospital in 1997-8. Altogether, 96 serum samples were obtained from patients with classical or definite RA according to the RA criteria revised by the ACR in $1987^{1}$; these included 83 women and 13 men with a mean age of 55 years (range 18-76). Mean disease duration was 7.8 years (range 2 months to 28 years), and 14 patients had been diagnosed as having early RA with disease duration of less than 1 year. Ninety serum samples were collected from patients with other rheumatic diseases (58 women and 32 men with comparable mean age of 52 years (range 19-82) and mean disease duration of 6.3 years). Their diagnoses are presented in table 1. Control normal serum samples were obtained from 37 age matched healthy volunteers who were elderly subjects from Vilnius Gerontology Centre and staff workers from Vilnius Experimental and Clinical Medicine Institute (31 women and six men of mean age of 54 years (range 19-88)). All blood samples were stored at $-20^{\circ} \mathrm{C}$ until analysed. Serum samples were tested without knowing the clinical details of the patients.

\section{CLINICAL MEASURES}

The following data were collected from the medical records of the patients with RA: disease duration, duration of morning stiffness, Ritchie articular index, erythrocyte sedimentation rate (ESR, $\mathrm{mm} / 1 \mathrm{st} \mathrm{h}$ ), haemoglobin values

Table 1 Diagnoses of 90 rheumatic disease control patients

\begin{tabular}{lc}
\hline Diagnosis & $\begin{array}{l}\text { Number of } \\
\text { patients }\end{array}$ \\
\hline Systemic lupus erythematosus (SLE) & 13 \\
Temporal arteritis and/or polymyalgia rheumatica & 6 \\
Systemic sclerosis (SSc) & 5 \\
Polymyositis or dermatomyositis & 3 \\
Mixed connective tissue disease (MCTD) & 2 \\
Raynaud's syndrome & 1 \\
Reactive arthritis (ReA) or morbus Reiter & 21 \\
Osteoarthritis & 21 \\
Psoriatic arthritis & 9 \\
Uric arthritis & 3 \\
Arthritis paraneoplastica & 3 \\
Lyme arthritis & 3 \\
\hline
\end{tabular}

$(\mathrm{Hb}, \mathrm{g} / \mathrm{l})$, presence of extra-articular manifestations (Sjögren's syndrome, rheumatoid nodules, rheumatoid vasculitis, pleuritis, conjunctivitis, Raynaud's syndrome, Felty's syndrome), the presence of hand deformity, and constitutional symptoms (loss of weight, anorexia, fever). Radiographs of the hands, feet, or both of all the patients with RA were interpreted by hospital radiologists who were unaware of the patients' clinical and laboratory data. The radiographs were evaluated for structural changes according to Steinbrocker's classification, ${ }^{31}$ which was also used to evaluate functional status. The disease activity score (DAS) was calculated as described by van Riel. $^{32}$

DETECTION OF AKA, ANCA, AND ANA BY INDIRECT IMMUNOFLUORESCENCE

AKA were detected using cryosections from the middle third of rat oesophagus as the antigen source. ${ }^{14}$ Serum samples, diluted to $1: 20$ in phosphate buffered saline (PBS), $\mathrm{pH}$ 7.2, were applied to the tissue and incubated at room temperature for 30 minutes in a moist chamber. After two washings, fluorescein conjugated rabbit antihuman IgG (FITC, Dakopatts F202, Denmark) diluted in PBS was added, incubated for 30 minutes, washed, and mounted with mounting medium, $\mathrm{pH}$ 8.3. All sections were read independently by two observers and positive and negative control serum samples were included in each run. AKA positive serum gave distinct laminar or speckled fluorescent staining of the superficial layer (stratum corneum) of the rat oesophagus epithelium. Serum samples with positive fluorescence were subsequently titrated.

ANCA were detected on ethanol fixed leucocytes as previously described. ${ }^{33}{ }^{34}$ Serum samples were diluted to 1:20 in PBS. Fluorescence patterns were described as "cytoplasmic" or cANCA when a diffuse granular cytoplasmic staining was seen, and as "perinuclear" or pANCA when a perinuclear or nuclear pattern was observed in the neutrophils and monocytes. For differentiation of pANCA from ANA, samples positive for ANCA and with positive fluorescence in lymphocytes and neutrophils were titrated for titre determination on both cell types. pANCA were present if reactivity was seen solely with neutrophils and monocytes or in at least two dilution steps higher than the lymphocyte reaction. All ANCA positive serum samples were further tested by ELISA for reactivity to proteinase 3 (PR3), myeloperoxidase (MPO), and lactoferrin (LF).

ANA were detected on commercial Hep-2 cell substrate (ImmunoConcepts, Sacramento, CA, USA), as described in detail elsewhere, ${ }^{35} 36$ at a $1: 160$ serum dilution in PBS. Two observers, using positive and negative reference samples in each run, evaluated the results. Fluorescence intensity was scored in four categories ranging from 0 to +++ , and staining patterns were described as "homogeneous", "fine speckled", "coarse speckled", "nucleolar", and "centromere". All ANA positive serum samples with homogeneous patterns were further 
tested by ELISA for anti-DNA and antihistone antibodies, serum samples with speckled patterns were tested for anti-Ro(SS-A), anti$\mathrm{La}(\mathrm{SS}-\mathrm{B})$, and by haemagglutination for antibodies to $\mathrm{nRNP}$ and $\mathrm{Sm}$.

ELISA FOR IGM AND IGA RHEUMATOID FACTORS $\mathrm{RF}$ of IgM and IgA isotypes were detected by ELISA as described by Høier-Madsen et $a l^{\beta^{7}}$ and Vejtorp et $a l^{8}$ with a few modifications. Briefly, polypropylene microtitre plates (MaxiSorp, Nunc-Immuno Plates I-96F, Roskilde, Denmark) were coated with in house purified human IgG. Cohn fraction II was used for IgM $\mathrm{RF}$ and affinity purified human IgG was used for IgA RF detection to avoid IgA contamination. The antigen concentration used was $100 \mu \mathrm{g} / \mathrm{ml}(2 \mu \mathrm{g} / \mathrm{ml}$ in each well), diluted in carbonate buffer, $\mathrm{pH}$ 9.6. After blocking with $\mathrm{PBS} / 1 \%$ bovine serum albumin (BSA), $\mathrm{pH} 7.2$, overnight at $4^{\circ} \mathrm{C}$ and washing, the microtitre plates were ready for use. The patient serum samples and positive and negative control samples were diluted to $1: 100$ in PBS/ $1 \% \mathrm{BSA}, \mathrm{pH}$ 7.2 , and added to the appropriate wells in duplicate. Binding of RF was detected by peroxidase conjugated rabbit $\mathrm{F}(\mathrm{ab})_{2}$ antihuman IgM (Dako P322, Denmark) or rabbit antihuman IgA (Dako P405, Denmark), diluted to $1: 8000$ and $1: 2000$ in $\mathrm{PBS} / 1 \% \mathrm{BSA}, \mathrm{pH} 7.2$, respectively. The colour reaction was performed with $o$-phenylenediamine (OPD) (Kem-En-Tec, Denmark), dissolved in a $0.1 \mathrm{M}$ citric acid phosphate buffer, $\mathrm{pH} 5.0$, and $\mathrm{H}_{2} \mathrm{O}_{2}$ mixture. The reaction was stopped using $1 \mathrm{M}$ sulphuric acid. The plates were read at $492 \mathrm{~nm}$ with $620 \mathrm{~nm}$ reference filters in an ELISA plate reader (Easy Reader EAR 400 Atc, Triolab). The WHO international reference preparation for RF containing $100 \mathrm{IU}$ in one ampoule ${ }^{39}$ was used as reference for IgM RF in this study and the results were expressed in IU $/ \mathrm{ml}$. In each experiment a positive and a negative local reference serum sample was included, representing a mixture of IgM RF positive or IgA RF positive patient serum. IgA RF concentrations were expressed in arbitrary units per millilitre $(\mathrm{U} / \mathrm{ml})$ using the local standard. Cut off levels were $>17 \mathrm{IU} / \mathrm{ml}$ for IgM RF based on $2 \mathrm{SD}$ above the mean level of IgM RF in serum samples from 98 patients with infectious disease, and $\geqslant 25 \mathrm{U} / \mathrm{ml}$ for IgA RF, set at $3 \mathrm{SD}$ above the mean level of IgA RF in serum samples from 532 healthy subjects. Intra-assay and interassay variations were $<10 \%$ for all assays.

DETECTION OF PR3-, MPO- AND LF-ANCA

The method developed by Heegaard et $a l^{40}$ was used to purify PR3 from neutrophil azurophilic granules. MPO was purified as previously reported, ${ }^{41}$ and LF was purified from secondary granules of neutrophils using the technique described in detail elsewhere. ${ }^{42}$ Antibodies against PR3, MPO, and LF were detected by ELISA according to Wiik et al. ${ }^{34}$ In brief, wells were coated by incubating the microtitre plates overnight at $4^{\circ} \mathrm{C}$ with $100 \mu \mathrm{l} /$ well PR3 at $1 \mu \mathrm{g} /$ $\mathrm{ml}, \mathrm{MPO}$ at $2 \mu \mathrm{g} / \mathrm{ml}$, and $\mathrm{LF}$ at $10 \mu \mathrm{g} / \mathrm{ml}$ diluted in $0.05 \mathrm{M}$ carbonate buffer, $\mathrm{pH}$ 9.6. The patient, positive and negative control serum samples were diluted to $1: 100$ in incubation buffer containing $0.05 \mathrm{M}$ Tris, $0.15 \mathrm{M} \mathrm{NaCl}, 0.2 \% \mathrm{BSA}$, and $0.05 \%$ Tween 20, pH 7.5 (except in the LF-ANCA assay, the incubation buffer contained $1 \%$ BSA and $1 \%$ Tween 20). The local standard serum samples were used to establish standard curves in each assay. Bound antibodies were detected by incubation with alkaline phosphatase conjugated goat antihuman IgG, $\gamma$ chain specific (Sigma), diluted to 1:5000 for PR3-ANCA and MPO-ANCA assays, and to $1: 4000$ for the LF-ANCA assay. Colour development was completed with p-nitrophenylphosphate (Sigma) in $1 \mathrm{M}$ diethanolamine buffer, $\mathrm{pH} 9.8$. The absorbance was read at $405 \mathrm{~nm}$ in the automated ELISA plate reader. Serum antibody levels were expressed as arbitrary units per $\mathrm{ml}$ serum. The cut off levels were $10 \mathrm{U} / \mathrm{ml}$ for PR3-ANCA and MPO-ANCA, and $4 \mathrm{U} / \mathrm{ml}$ for LF-ANCA. The cut off levels representing the lower limit of positivity were calculated from the mean levels +3 SD of 100 normal serum samples. Intra-assay and interassay variations were $<10 \%$ for all assays.

DETECTION OF ANTI-DNA, ANTIHISTONE, ANTI-RO(SS-A), ANTI-LA(SS-B) ANTIBODIES Anti-dsDNA (IgG) levels were measured by ELISA (Varelisa; Pharmacia \& Upjohn Diagnostics GmbH \& Co KG, Freiburg, Germany), and antihistone (IgG), anti-Ro(SS-A) (IgG), anti-La(SS-B) (IgG) were assayed by ELISAs (Diastat; Shield Diagnostics Ltd., Dundee, UK) according to the manufacturer's instructions.

DETECTION OF ANTIBODIES TO THE

"EXTRACTABLE NUCLEAR ANTIGENS"(ENA) Sm/nRNP

ENA were prepared from calf thymus nuclei according to Sharp et al. ${ }^{43}$ Briefly, calf thymus was minced, homogenised in sucrose solution, filtered, and centrifuged. The insoluble material was disrupted in 0.1 ionic strength

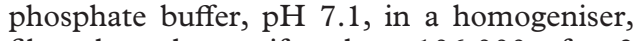
filtered, and centrifuged at $106000 \mathrm{~g}$ for 2 hours. Sodium acetate, $10 \mathrm{ml} / \mathrm{ml}$ supernatant, was added and dissolved. Six volumes of ethanol were added and the precipitate was brought down by centrifugation. Finally, the precipitate was solubilised in $0.15 \mathrm{M} \mathrm{NaCl}$ and lyophilised. Anti-nRNP and anti-Sm were then detected using passive haemagglutination as described by Høier-Madsen et al. ${ }^{44}$

STATISTICAL ANALYSES

Each variable was analysed within each group of patients and controls (mean, standard deviation (SD), and range). Mean differences were tested using the Student's $t$ test (two tailed). Comparison of proportions was performed using $\chi^{2}$ analysis with Yates's correction to assess the statistical significance of data. Correlation was sought using Pearson's or Spearman's $\left(r_{\mathrm{s}}\right)$ correlation coefficient when appropriate. To assess the diagnostic value of AKA and other serological markers we calculated the following indices: sensitivity, specificity, positive predictive value (PPV) - that is, 
Table 2 Rates of occurrence of serological markers obtained with IIF and ELISA assays in patients with and without $R A$, and healthy control groups

\begin{tabular}{llcl}
\hline Serological variables & $R A$ patients $n=96(\%)$ & $\begin{array}{l}\text { Patients with rheumatic diseases } \\
\text { other than } R A=90(\%)\end{array}$ & $\begin{array}{l}\text { Healthy donors } \\
n=37(\%)\end{array}$ \\
\hline AKA & $42(44)^{\star}$ & $3(3)$ & $1(3)$ \\
ANCA & $32(33)^{\star \star}$ & $17(19)$ & $3(8)$ \\
pANCA & 32 & 16 & 2 \\
cANCA & 0 & 1 & 1 \\
ANA & $49(51)$ & $38(42)$ & $3(8)$ \\
Homogeneous & 32 & 21 & 1 \\
Speckled & 12 & 10 & 0 \\
Nucleolar & 6 & 10 & 1 \\
Centromere & 3 & 4 & 0 \\
IgA RF & $74(77)^{\star}$ & $20(22)$ & 0 \\
IgM RF & $75(78)^{\star}$ & $19(21)$ & $1(3)$ \\
IgA RF + IgM RF & $69(72)^{\star}$ & $15(17)$ & 0 \\
PR3-ANCA & $1(1)$ & 0 & $1(3)$ \\
MPO-ANCA & $4(4)$ & $1(1)$ & 0 \\
LF-ANCA & $18(19)$ & $10(11)$ & 0 \\
Anti-dsDNA & $10(10)$ & $9(10)$ & 0 \\
Antihistone & $5(5)$ & $7(8)$ & \\
Anti-Ro(SS-A) & $4(4)$ & $3(3)$ & \\
\hline
\end{tabular}

For definitions of abbreviations, see text.

${ }^{\star} \mathrm{p}<0.0001 ;{ }^{\star \star} \mathrm{p}=0.025$ ( $\chi^{2}$ test $)$.

the probability of the diagnosis - and negative predictive value (NPV) - that is, the probability of excluding the diagnosis. Analysis of a possible relationship between serological markers and clinical or laboratory features of RA patients was performed. A multiple regression analysis was used to identify the independent impact of selected clinical and paraclinical findings on the characteristics of RA. In all instances $p$ values of $<0.05$ were considered significant.

\section{Results}

IIF AND ELISA ASSAYS

The positive test results obtained in patients and healthy controls are summarised in table 2 . The proportion of AKA positive serum samples was significantly higher in the patients with RA than in the other groups $(\mathrm{p}<0.0001)$. AKA were found in $42(44 \%)$ of the 96 patients with RA, six of whom had early RA. In serum samples from patients with RA the titres of positivity for AKA ranged from 1:20 (most common) to $\geqslant 1: 1280$. Only two serum samples were positive at a titre of $\geqslant 1: 1280$. The most common AKA titre in patients with early RA was 1:640. In the disease control group AKA were found in three cases at the following titres: 1:40 (patient with systemic sclerosis ( $\mathrm{SSc}$ )), 1:80 (patient with polymyalgia rheumatica), and 1:1280 (patient with systemic lupus erythematosus (SLE)). In one serum sample from normal subjects AKA were positive at a titre of 1:640. Almost all AKA positive serum samples showed a distinct laminar fluorescence pattern of the stratum corneum except two

Table 3 Sensitivity, specificity, positive predictive value (PPV), and negative predictive value (NPV) of serological markers in 96 patients with $R A$ with disease duration of about 8 years

\begin{tabular}{lllll}
\hline Serological marker & Sensitivity (\%) & $\begin{array}{l}\text { Diagnostic } \\
\text { specificity (\%) }\end{array}$ & PPV (\%) & NPV (\%) \\
\hline AKA & 44 & 97 & 91 & 69.5 \\
IgA RF & 77 & 84 & 79 & 83 \\
IgM RF & 78 & 84 & 78 & 84 \\
IgA RF + IgM RF & 72 & 88 & 82 & 81 \\
AKA + IgA RF + IgM RF & 35 & 98 & 92 & 67 \\
ANCA & 33 & 84 & 61.5 & 63 \\
ANA & 51 & 68 & 54 & 64 \\
\hline
\end{tabular}

For definitions of abbreviations, see text. which had a speckled fluorescence pattern (patients with RA and SLE).

The proportions of serum samples positive for RF $(p<0.0001)$ and ANCA $(p=0.025)$ were also significantly higher in patients with RA. Sixty nine $(72 \%)$ patients with RA had increased levels of both RF isotypes. Only two normal subjects were positive for IgM RF with low levels. The overall incidence of ANCA in patients with RA was $33 \%$, and all these serum samples had a pANCA fluorescence pattern. The antigen specificity could be determined in $19(59 \%)$ of the 32 pANCA positive patients with RA. Four pANCA positive patients had antibodies against more than one antigen. Three serum samples from patients with RA were positive for both LF-ANCA and MPOANCA and one sample was positive for both LF-ANCA and PR3-ANCA. Eighteen pANCA positive patients were positive for LF-ANCA, four were positive for MPOANCA, and one for PR3-ANCA. In the rheumatic disease control group pANCA were found in 16 cases (seven with reactive arthritis ( $R e A)$, five with SLE, two with SSc, and two with mixed connective tissue disease (MCTD)). cANCA were found only in one ReA serum sample that was PR3-ANCA negative and in one normal serum with strong PR3ANCA reactivity.

The most common ANA staining pattern was "homogeneous". Some serum samples gave rise to a mixed staining pattern ("homogeneous" + "speckled"/or + "nucleolar", or "homogeneous" + "centromere"). Positivity for ANA, anti-dsDNA, and antihistone antibodies in RA and rheumatic disease controls was not statistically different. Very few serum samples were positive for anti-Ro(SS-A) in RA and rheumatic disease control groups, and only one patient with RA who had Sjögren's syndrome was positive for anti-Ro(SS-A). No serum samples contained anti-La(SS-B) or anti-nRNP/Sm.

DiAgNOSTIC VALUE

The diagnostic value of the serological markers for RA is summarised in table 3. AKA showed a diagnostic specificity of $97 \%$ and a PPV of $91 \%$. AKA with coexisting RF of both isotypes had a specificity of $98 \%$ and a PPV of $92 \%$ for RA. Of the 34 patients with RA who were positive for this combined set of serological markers, five (15\%) had early RA.

ASSOCIATIONS OF RA DISEASE VARIABLES WITH AKA, RHEUMATOID FACTORS, AND ANCA

Clinical and paraclinical associations with AKA, IgA RF, and ANCA positivity are analysed in table 4 (data not shown for $\operatorname{IgM}$ $\mathrm{RF}$ ). We did not find significant differences in AKA positivity with respect to age, sex, disease duration, duration of morning stiffness, the presence of hand deformity, and some laboratory observations (ESR, $\mathrm{Hb}$ values, and positivity for ANCA or ANA). In patients with RA, IgA RF were significantly associated with AKA positivity and the mean levels of IgA RF were higher in AKA positive than in AKA negative patients with RA. The prevalence of 
Table 4 Data distribution depending on AKA, IgA RF, and ANCA positivity in 96 patients with RA (mean (SD) values shown where appropriate)

\begin{tabular}{|c|c|c|c|c|c|c|c|c|c|}
\hline $\begin{array}{l}\text { Clinical and paraclinical } \\
\text { variables }\end{array}$ & $\begin{array}{l}\text { AKA positive } \\
(n=42)\end{array}$ & $\begin{array}{l}\text { AKA negative } \\
(n=54)\end{array}$ & p value & $\begin{array}{l}\operatorname{Ig} A \text { RF positive } \\
(n=74)\end{array}$ & $\begin{array}{l}\text { IgA RF negative } \\
(n=22)\end{array}$ & $p$ value & $\begin{array}{l}\text { ANCA positive } \\
(n=32)\end{array}$ & $\begin{array}{l}\text { ANCA negative } \\
(n=64)\end{array}$ & $p$ value \\
\hline Age (years) & $56(9.2)$ & $55(12.5)$ & NS & $57(9.5)$ & $50(14.3)$ & $0.03^{\star \star}$ & $57(13)$ & $54(10)$ & NS \\
\hline Male/female (n) & $7 / 35$ & $6 / 48$ & NS & $10 / 64$ & $3 / 19$ & NS & $4 / 28$ & $9 / 55$ & NS \\
\hline Duration of disease (years) & $6.9(6.2)$ & $8.7(7.9)$ & NS & $8(7.5)$ & $7.4(6.5)$ & NS & $10(7.8)$ & $6.7(6.7)$ & $0.03^{\star \star}$ \\
\hline Morning stiffness (hours) & $2.2(0.8)$ & $1.9(0.9)$ & NS & $2(0.9)$ & $1.7(0.9)$ & NS & $2(0.9)$ & $1.9(0.9)$ & NS \\
\hline Hand deformity (n) & 20 & 21 & NS & 33 & 8 & NS & 18 & 23 & NS \\
\hline Constitutional symptoms (n) & 30 & 26 & $0.02^{\star}$ & 50 & 6 & $0.0008^{\star}$ & 19 & 37 & NS \\
\hline Extra-articular symptoms (n) & $18 \dagger$ & $9 \ddagger$ & $0.005^{\star}$ & 24 & 3 & NS & $17 \Phi$ & $10 \pi$ & $0.0001^{\star}$ \\
\hline Functional class $\geqslant$ II (n) & 41 & 33 & $<0.0001^{\star}$ & 63 & 11 & $0.0006^{\star}$ & 30 & 44 & $0.006^{\star}$ \\
\hline Steinbrocker's score $\geqslant 2(\mathrm{n})$ & 27 & 22 & $0.02^{\star}$ & 39 & 10 & NS & 22 & 27 & $0.01^{\star}$ \\
\hline Ritchie index $>15(n)$ & 42 & 34 & $<0.0001^{\star}$ & 63 & 13 & $0.008^{\star}$ & 29 & 47 & $0.05^{\star}$ \\
\hline DAS (range) & $\begin{array}{l}6.5(0.9) \\
(4.2-8.4)\end{array}$ & $\begin{array}{l}4.2(0.7) \\
(2.9-6.8)\end{array}$ & $<0.0001^{\star \star}$ & $\begin{array}{l}5.4(1.4) \\
(3.1-8.4)\end{array}$ & $\begin{array}{l}4.6(1.2) \\
(2.9-7.8)\end{array}$ & $0.01^{\star \star}$ & $\begin{array}{l}5.7(1.3) \\
(3.7-7.9)\end{array}$ & $\begin{array}{l}5(1.4) \\
(2.9-8.4)\end{array}$ & $0.02^{\star \star}$ \\
\hline $\operatorname{ESR}(\mathrm{mm} / 1 \mathrm{st} \mathrm{h})$ & $33.2(15)$ & $32.7(14.9)$ & NS & $34.2(15.3)$ & $29.2(12.6)$ & NS & $35(16$ & $31.8(14.3)$ & NS \\
\hline Haemoglobin (g/l) & $116(14.8)$ & $115(14.5)$ & NS & $115.5(14.6)$ & $116.2(14.7)$ & NS & $114.5(12.8)$ & $117.8(45.6)$ & $0.03^{\star \star}$ \\
\hline IgA RF positive (n) & 37 & 37 & $0.02^{\star}$ & - & - & & 25 & 49 & NS \\
\hline IgA RF levels (AU/ml) & $73.4(32.6)$ & $53.4(38.8)$ & $0.007^{\star \star}$ & - & - & & $68.6(37.2)$ & $58.9(37.4)$ & NS \\
\hline IgM RF positive (n) & 36 & 39 & NS & 69 & 6 & $<0.0001^{\star}$ & 26 & 49 & NS \\
\hline IgM RF levels (IU/ml) & $165.8(36.4)$ & $128.4(31.6)$ & NS & $181(131)$ & $22(39.2)$ & $<0.0001^{\star \star}$ & $191.4(149.5)$ & $121.4(120.7)$ & $0.025^{\star \star}$ \\
\hline IgA, IgM RF positive (n) & 34 & 35 & NS & - & - & & 24 & 45 & NS \\
\hline ANCA positive (n) & 18 & 14 & NS & 25 & 7 & NS & - & - & \\
\hline ANA positive (n) & 22 & 27 & NS & 38 & 11 & NS & 20 & 29 & NS \\
\hline
\end{tabular}

${ }^{\star} \chi^{2}$ test.

$\star \star$ Student's $t$ test.

†Including rheumatoid vasculitis (7), rheumatoid nodules (5), pleuritis (5), Sjögren's syndrome (1), Felty's syndrome (1), conjunctivitis (1).

łIncluding rheumatoid nodules (4), rheumatoid vasculitis (3), conjunctivitis (2), Raynaud's syndrome (1), pleuritis (1).

IIncluding rheumatoid vasculitis (8), pleuritis (5), rheumatoid nodules (3), conjunctivitis (2), Felty's syndrome (1), Raynaud's syndrome (1).

१ๆIncluding rheumatoid nodules (6), vasculitis (2), conjunctivitis (1), pleuritis (1), Sjögren's syndrome (1).

Some patients had more than one extra-articular symptom.

For definitions of abbreviations, see text.

extra-articular features and constitutional symptoms was also statistically higher in AKA positive patients. In addition, all AKA positive patients had a Ritchie index of more than 15. With regard to functional capacity, disease activity, and radiological progression, AKA positive patients with RA had more severe underlying disease than AKA negative patients. A statistically significant correlation was found between AKA titres and the DAS $\left(r_{\mathrm{s}}=0.78\right.$, $\mathrm{p}<0.005)$, functional status $\left(r_{\mathrm{s}}=0.42\right.$, $\mathrm{p}<0.005)$, and IgA RF levels $\left(r_{\mathrm{s}}=0.24, \mathrm{p}<0.05\right)$.

Patients with RA who were positive for IgA $\mathrm{RF}$ were older than those who were negative. Positivity for IgA RF was significantly associated with constitutional symptoms, functional disability, and higher Ritchie indices. Higher IgA RF levels correlated with a higher DAS $(r=0.29, \mathrm{p}<0.01)$ and worse functional status $\left(r_{\mathrm{s}}=0.26, \mathrm{p}<0.01\right)$. A statistically strong correlation was found between IgA RF and IgM RF levels $(r=0.73, \mathrm{p}<0.0001)$. Only two patients with RA had an isolated increase in IgA RF and both were negative for AKA. However, IgM RF did not correlate with the parameters related to IgA RF. We found 16 seronegative RA patients for both RF isotypes, three (19\%) of whom were positive for AKA.

Patients with RA who were positive for pANCA had significantly longer disease duration than those who were negative. Compared with pANCA negative RA patients, pANCA positive patients had a more severe disease course with a worse functional state and more advanced radiological damage. Patients positive for pANCA also had significantly higher inflammatory activity, as estimated by the DAS, mean blood haemoglobin concentration, and higher mean levels of IgM RF. Perinuclear ANCA were significantly associated with extraarticular manifestations in patients with RA. Out of 10 patients with rheumatoid vasculitis, eight with RA were positive for pANCA $(p=0.0009)$. The antigen specificity could be determined in only two patients with rheumatoid vasculitis, both of whom had antibodies against lactoferrin.

Multiple regression analysis was applied to identify the independent impact of selected clinical and paraclinical findings on the presence of radiological progression and functional capacity. Radiological damage was dependent on disease duration and was significantly associated with worse functional capacity $(p<0.0001)$. There was no relationship between positivity for AKA, IgA RF, IgM RF, ANCA, or ANA and radiographic score. However, positivity for AKA was significantly correlated with the functional capacity $(p=0.0001)$. Also, ESR was significantly associated with compromised function $(p=0.013)$.

\section{Discussion}

This study confirms that AKA is a serological marker with a particular clinical value in adult RA. ${ }^{14}$ Antikeratin antibodies were detectable in $44 \%$ of our patients with RA of about 8 years' duration, and these findings agree with those of earlier studies in advanced RA. ${ }^{21}{ }^{25}$ Several studies have recently reported that the frequency of anticyclic citrullinated peptide (antiCCP) antibodies in early RA can approach $70 \% .{ }^{28-30}$ In our study six of 14 patients with early RA were AKA positive and the AKA titres were found to be much higher than in patients with RA of longer duration. However, the number of patients with early RA was too small to warrant significant conclusions about the frequency of AKA and their value in early RA. Classically, the laminar staining of the stratum corneum is interpreted as a positive finding. Whether the two serum samples positive for AKA in our study which had speckled stratum corneum staining recognise citrullinated peptides ${ }^{28}{ }^{29}$ like most other AKA, is not known at present. 
A cut off dilution of serum set at 1:20 gave a diagnostic specificity of $97 \%$ and a PPV of $91 \%$, which agrees with data from other groups for patients with advanced RA. ${ }^{21}$ In addition, the diagnostic specificity and PPV of AKA in our patients with long standing disease were comparable to the values associated with anti$\mathrm{CCP}$ antibodies in patients with RA of recent onset. ${ }^{29}$ Our findings on the diagnostic value of AKA in RA add support to the contention that the presence of AKA is not related to disease duration ${ }^{132021}$ and can be found with the same specificity in patients with early and chronic RA. We found that diagnostic efficacy was greatest when tests for AKA, IgA RF, and IgM $\mathrm{RF}$ were used in combination. The higher diagnostic value of the combined set of serological markers can be explained by the fact that associations of markers are rare in control serum samples.

In this study we found that the RF of $\operatorname{IgA}$ and IgM isotypes are the most sensitive markers and can be found in more than $70 \%$ of patients with RA, but they are less disease specific and have a far lower PPV than AKA because their diagnostic values have been influenced by a number of positive test results in patients with other rheumatic diseases and in healthy subjects. ${ }^{45}$ The observed prevalence of ANCA and the predominance of pANCA as the staining pattern in patients with RA are in accordance with the results of previous studies. $^{6-11}$ The ANCA immunofluorescence test had a diagnostic specificity comparable to IgA and IgM RF, but the low sensitivity (33\%) and low PPV (61.5\%) restricts its usefulness in diagnosing RA. Larger studies are needed for estimating the diagnostic value of ANCA in RA. The observed prevalence of ANA and specificity of the test in RA patients are in agreement with results from previous studies ${ }^{12}$; the low PPV is related to sensitivity and specificity. Nevertheless, only a few of the healthy subjects were positive for ANA at the same dilution, indicating that the rheumatoid inflammatory process - rather than age and sex-caused the ANA positivity.

We compared AKA detection with other diagnostic tests for RA and attempted to determine whether AKA positive patients belonged to a particular subgroup of RA. We confirmed that AKA are independent of the sex and age of the patients. ${ }^{132021}$ In our study, patients with RA whose serum samples were positive for AKA had significantly more radiological damage (as measured by the Steinbrocker radiographic score), much greater expressed functional disability, a higher prevalence of extraarticular and constitutional features, and more active disease than AKA negative patients. These results are consistent with those of previous studies which also showed positive associations between AKA and radiological damage ${ }^{30}$ functional disability, ${ }^{17}{ }^{18}$ extra-articular symptoms, ${ }^{1921}$ and disease activity. ${ }^{161821}$ All these findings suggest that AKA are associated with the most severe and active forms of RA. Nevertheless, using multiple regression analysis of our data, positivity for AKA was significantly correlated only with functional disability and did not reveal any association with radiological damage. By contrast, Kroot et al have reported that anti-CCP antibodies do not predict functional disability and have only a moderate predictive value on radiological damage in patients with RA of recent onset. ${ }^{30}$ However, their patients had recently diagnosed RA and were followed up for 6 years, while in our study almost all the patients had RA of long duration and different methods were used to evaluate functional capacity and radiological damage. Further similar studies are needed to evaluate the impact of AKA on function and joint damage in RA.

AKA in combination with RF may have a special significance in patients with RA. In this regard it was shown that 34 of 42 AKA positive patients with RA harboured RF of both isotypes, although AKA were also found in some seronegative patients. This is in keeping with other previously published studies. ${ }^{20}{ }^{21}$ In our study, IgA RF positivity and higher levels of IgA RF, but not IgM RF, were associated with AKA positivity in RA, whereas in previous studies a correlation between AKA titres and IgM RF levels has been reported. ${ }^{14-18} 2122$ We also found no association between AKA and ANA, in agreement with other authors, ${ }^{21}$ although in some earlier studies such a relation was found. ${ }^{1718} 22$

In our study $\operatorname{IgA} \mathrm{RF}$, but not $\operatorname{Ig} M \mathrm{RF}$, was associated with several clinical and paraclinical variables of RA. IgA RF was more often found in older patients with RA, in agreement with other authors. ${ }^{45}$ We confirmed that IgA RF correlates better with disease activity than IgM $\mathrm{RF}^{45-47}$ IgA RF levels were also correlated with a higher DAS, more compromised functional capacity, and higher Ritchie indices. This indicates that higher IgA RF levels relate to activity and functional outcome in RA, but not to radiological damage or extra-articular manifestations. Other groups have shown that IgA RF is associated with more erosive disease ${ }^{45} 4849$ and with extra-articular features. ${ }^{245}$ However, in accordance with findings from other studies, ${ }^{11}$ we found no associations between RF and ANA or ANCA positivity. We suggest that the different associations between RF isotypes and clinical variables of RA can be explained by the use of purified human IgG as antigen to measure RF by ELISA. ${ }^{45}$

Perinuclear ANCA are thought to occur in patients with RA, especially in patients with long standing disease. ${ }^{8}$ We found that pANCA positive patients had disease of significantly longer duration than pANCA negative patients, which indicates that ANCA could be a marker of chronic inflammation in RA. We found no relation between AKA and ANCA, but this finding needs to be confirmed in a larger study. ANCA positivity showed the same associations as AKA with regard to radiological joint damage, extra-articular manifestations, disease activity, and functional disability in our patients with RA, which agrees with the findings of other authors. ${ }^{11}$ Recently published data indicate that ANCA is a marker of progressive erosive disease in early RA. ${ }^{50}$ However, in multiple regression analysis of our data, 
no association was found between ANCA and radiological damage in patients with advanced RA.

In some previous studies it has been shown that pANCA are not associated with disease activity, ${ }^{78}$ although in others such an association has been found. ${ }^{11}$ In our study pANCA positivity was significantly associated with parameters indicating active RA such as higher DAS, low blood haemoglobin concentration, and higher levels of IgM RF, which suggests a severe disease course in ANCA positive patients.

ANCA from patients with RA recognise a number of antigens of granulocytes. ${ }^{8}$ In the present study an antigen target for pANCA could be determined in only 19 of the patients with RA, and lactoferrin was the most common antigen recognised. It has been proposed that MPO-ANCA ${ }^{51}$ and LF-ANCA ${ }^{52}$ in RA are associated with rheumatoid vasculitis. In our patients with RA, pANCA IIF was associated with the presence of rheumatoid vasculitis, although the number of patients positive for specific ANCA was low.

In conclusion, our data suggest that AKA are the most specific serological markers for RA and determination of AKA will be of value in the diagnosis of RA. In the presence of RF of the $\operatorname{IgA}$ and $\operatorname{IgM}$ isotypes, AKA strongly indicate RA. Furthermore, AKA may have some prognostic significance as the subgroup of patients with RA with positive AKA had more severe and active forms of the disease. Earlier identification of patients who are likely to have a more severe disease course could help in deciding on early active antirheumatic treatment. Patients with RA positive for ANCA and for AKA may suffer more joint destruction.

We thank Professor E Redaitiene and Dr J Dadoniene for help in obtaining the serum samples from healthy subjects (Experimental and Clinical Medicine Institute, Vilnius, Lithuania).

The studies of L Vasiliauskiene at the Statens Serum Institut in Copenhagen, Denmark were supported partially by a grant from the Danish Government.

1 Arnett FC, Edworthy SM, Bloch DA, McShane DJ, Fries JF, Cooper NS, et al. The American Rheumatism Association 1987 revised criteria for the classification of rheumatoid arthritis. Arthritis Rheum 1988;31:315-24.

2 Gioud-Paquet M, Auvinet M, Raffin T, Girard P, Bouvier $\mathrm{M}$, Lejeune E, et al. IgM rheumatoid factor (RF), IgA RF, IgE RF, and IgG RF detected by ELISA in rheumatoid arthritis. Ann Rheum Dis 1987;46:65-71.

3 Mageed RA, Kirwan JR, Thompson PW, McCarthy DA, Holb Orow EJ. Characterization of the size and composition of circulating immune complexes in patients with rheumatoid arthritis. Ann Rheum Dis 1991;50:231-6.

4 Shmerling RA, Delbanco TL. The rheumatoid factor: an Shmerling RA, Delbanco TL. The rheumatoid factor:
analysis of clinical utility. Am J Med 1991;91:528-34.

5 analysis of clinical utility. Am J Med 1991;91:528-34. Smolen JS. Rheumatoid arthritis. In: Maini RN, van
Venrooij WJ, eds. Manual of biological markers. Amsterdam: Venrooij WJ, eds. Manual of bio
Kluwer Academic, 1996:1-18.

6 Wiik A, Jensen E, Friis J. Granulocyte-specific antinuclear factors in synovial fluids and sera from patients with rheumatoid arthritis. Ann Rheum Dis 1974;33:515-22.

7 Savige JA, Gallicchio MC, Stockman A, Cunningham TJ, Rowley MJ, Georgiou T, et al. Anti-neutrophil cytoplasm antibodies in rheumatoid arthritis. Clin Exp Immunol 1991;86:92-8.

8 Mulder AH, Horst G, van Leeween MA, Limburg PC, Kallenberg CGM. Antineutrophil cytoplasmic antibodies in rheumatoid arthritis: characterization and clinical correlations. Arthritis Rheum 1993;36:1054-60.

9 Röther E, Schochat T, Peter HH. Antineutrophil cytoplasmic antibodies (ANCA) in rheumatoid arthritis: a prospective study. Rheumatol Int 1996;15:231-7.

10 Afeltra A, Sebastiani GD, Galeazzi M, Caccavo D, Ferri GM, Marcolongo R, et al. Antineutrophil cytoplasmic antiGM, Marcolongo R, et al. Antineutrophil cytoplasmic anti-
bodies in synovial fluid and in serum of patients with rheumatoid arthritis and other types of synovitis. J Rheumatol 1996;23:10-5.
11 Mustila A, Korpela M, Mustonen J, Helin H, Huhtala H, Soppi E, et al. Perinuclear antineutrophil cytoplasmic antiSoppi E, et al. Perinuclear antineutrophil cytoplasmic anti-
body in rheumatoid arthritis: a marker of severe disease body in rheumatoid arthritis: a marker of severe disease
with associated nephropathy. Arthritis Rheum 1997;40: with assoc.

12 Tan EM, Feltkamp TE, Smolen JS, Butcher B, Dawkins R, Fritzler MJ, et al. Range of antinuclear antibodies in "healthy" individuals. Arthritis Rheum 1997;40:1601-11.

13 Nienhuis RLF, Mandema EA, Smids C. A new serum factor in patients with rheumatoid arthritis: the antiperinuclear factor. Ann Rheum Dis 1964;23:302-5.

14 Young BJJ, Mallya RK, Leslie RDG, Clarck CJM, Hamblin TJ. Anti-keratin antibodies in rheumatoid arthritis. BMJ 1979;2:97-9.

15 Johnson GD, Carvalho A, Holborrow EJ, Goddard DH, Russel G. Antiperinuclear factor and keratin antibodies in rheumatoid arthritis. Ann Rheum Dis 1981;40:263-6.

16 Mallya RK, Young BJJ, Pepys MB, Hamblin TJ, Mace BEW, Hamilton EBD. Anti-keratin antibodies in rheumatoid arthritis: frequency and correlation with other features of arthritis: frequency and correlation with other feat

17 Ordeig J, Guardia J. Diagnostic value of antikeratin antibodies in rheumatoid arthritis. J Rheumatol 1984;11:602-4.

18 Hajiroussou VJ, Skingle J, Gillett AP, Webley M. Significance of antikeratin antibodies in rheumatoid arthritis. J Rheumatol 1985;12:57-9.

19 Youinou P, Le Goff P, Colaco CB, Thivolet J, Tater D, Viac $\mathrm{J}$, et al. Antikeratin antibodies in serum and synovial fluid show specificity for rheumatoid arthritis in a study of connective tissue diseases. Ann Rheum Dis 1985;44:450-4.

20 Kirstein H, Mathiesen FK. Antikeratin antibodies in rheumatoid arthritis. Scand J Rheumatol 1987;16:331-7.

21 Vincent C, Serre G, Lapeyre F, Fournié B, Ayrolles C, Fournié A, et al. High diagnostic value in rheumatoid Fournie A, et al. High diagnostic value in rheumatoid esophagus epithelium, so-called 'antikeratin antibodies'. esophagus epithelium, so-called

22 Scott DL, Delamere JP, Jones LJ, Walton KW. Significance of laminar antikeratin antibodies to rat esophagus in rheumatoid arthritis. Ann Rheum Dis 1981;40:267-71.

23 Paimela L, Gripenberg M, Kurki P, Leirisalo-Repo M. Antikeratin antibodies: diagnostic and prognostic markers for early rheumatoid arthritis. Ann Rheum Dis 1992;51: 743-6.

24 Kurki P, Aho K, Palosuo T, Heliövaara M. Immunopathology of rheumatoid arthritis: antikeratin antibodies precede the disease. Arthritis Rheum 1992;35:914-7.

25 Hoet RM, van Venrooij WJ. The antiperinuclear factor (APF) and antikeratin antibodies (AKA) in rheumatoid arthritis. In: Smolen JS, Kalden JR, Maini RN, eds. Rheumatoid arthritis. Berlin, Heidelberg: Springer-Verlag, 1992:299-318.

26 Sebbag M, Simon M, Vincent C, Masson-Bessiére C, Girbal E, Durieux JJ, et al. The antiperinuclear factor and the so-called antikeratin antibodies are the same rheuma-
toid arthritis-specific autoantibodies. J Clin Invest 1995;95: 2672-9

27 Vincent C, de Keyser F, Masson-Bessiere C, Sebbag M, Veys EM, Serre G. Anti-perinuclear factor compared with the so called "antikeratin" antibodies to human epidermis filaggrin, in the diagnosis of arthritides. Ann Rheum Dis 1999;58:42-8.

28 Schellekens GA, de Jong BAW, van den Hoogen FHJ, van de Putte LBA, van Venrooij WJ. Citrulline is an essential constituent of antigenic determinants recognized by rheumatoid arthritis-specific autoantibodies. J Clin Invest 1998; 101:273-81.

29 Schellekens GA, Visser H, de Jong BAW, van den Hoogen FHJ, Hazes JMW, Breedveld FC, et al. The diagnostic properties of rheumatoid arthritis antibodies recognizing a cyclic citrullinated peptide. Arthritis Rheum 2000;43:15563.

30 Kroot EJJA, de Jong BAW, van Leeuwen MA, Swinkels H, van den Hoogen FHJ, van't Hof M, et al. The prognostic value of anti-cyclic citrullinated peptide antibody in patients with recent-onset rheumatoid arthritis. Arthritis Rheum 2000;43:1831-5

31 Steinbrocker O, Traeger $\mathrm{CH}$, Batterman RC. Therapeutic criteria in rheumatoid arthritis. JAMA 1949;140:659-62.

32 Van Riel PL. Disease assessment and outcome in rheumatoid arthritis. Rheumatol Europe 1994;23:128-9.

33 Wiik A. Delineation of a standard procedure for indirect immunofluorescence detection of ANCA. Acta Pathol Microbiol Immunol Scand 1989;97(suppl 6):12-3.

34 Wiik A, Rasmussen N, Wieslander J. Methods to detect autoantibodies to neutrophilic granulocytes. In: van Venrooij WJ, Maini RN, eds. Manual of biological markers of disease. Dordrecht: Kluwer Academic, 1993:A9:1-14.

35 Humbel RL. Detection of antinuclear antibodies by immunofluorescence. In: van Venrooij WJ, Maini RN, eds. Manual of biological markers of disease. Dordrecht: Kluwer Academic, 1993:A2:1-16.

36 Tan EM. Autoantibodies to nuclear antigens (ANA): their immunobiology and medicine. Adv Immunol 1982;33: 167-240.

37 Høier-Madsen M, Nielsen LP, Møller S. Determination of IgM rheumatoid factor by enzyme-linked immunosorbent assay (ELISA). Ugeskr Læg 1986;148:2018-21.

38 Vejtorp M, Høier-Madsen M, Halberg P. Enzyme-linked immunosorbent assay for determination of IgM rheumatoid factor. Scand J Rheumatol 1979;8:65-70.

39 Anderson SG, Bentzon MW, Hauba V, Krage B. International reference preparation of rheumatoid arthritis serum. Bull WHO 1970;42:311-8. 
40 Heegaard NHH, Jakobsen DR, Klattschou D. Purification of Wegener's granulomatosis autoantigen, proteinase 3 , from neutrophils by triton X-114 extraction of azurophilic granules. Anal Biochem 1997;253:259-62.

41 Olsson I, Olofsson T, Odeberg H. Myeloperoxidasemediated iodination in granulocytes. Scand J Haemato 1972;9:483-91.

42 Heegaard NHH, Brimnes J. Comparison of heparin-binding to lactoferrin from human milk and from human granulocytes by means of affinity capillary electrophoresis. Electrophoresis 1996;17:1916-20.

43 Sharp GC, Irvin WS, Tan EM, Gould RG, Holman HR. Mixed connective tissue disease - an apparently distinct rheumatic disease syndrome associated with a specific antibody to an extractable nuclear antigen (ENA). Am J Med 1972;52:148-59.

44 Høier-Madsen M, Andersen MG. Microhaemagglutination test for detection of antibodies to "extractable nuclear anti-
gen" (ENA). Comparative investigation in different groups of "ENA). Comparative investigation in different groups Læg 1980;142:2627-30.

45 Houssien DA, Jonsson T, Davies E, Scott DL. Rheumatoid factor isotypes, disease activity and the outcome of

46 Van Zeben D, Hazes JMW, Zwindermann AH, Cats A, van der Voort EAM, Breedveld FC. Clinical significance of rheumatoid factors in early rheumatoid arthritis: results of follow-up study. Ann Rheum Dis 1992;51:1029-35.

47 Fouquet B, Renoux M, Eveleich M, Barados P, Valat J. Rheumatoid factor isotypes and severity of rheumatoid polyarthritis. Rev Rhum Mal Osteoartic 1987;54:31-5.

48 Jorgensen C, Legouffe MC, Bologna C, Brochier J, Sany J. IgA isotype rheumatoid factor in rheumatoid arthritis: clinical implications. Clin Exp Rheumatol 1996;14:301-4.

49 Teitsson I, Witrmington RH, Seifert MH, Valdimarsson H. Prospective study of early rheumatoid arthritis. Prognostic value of IgA rheumatoid factor. Ann Rheum Dis 1984;43: value of

50 Mustila A, Paimela L, Leirisalo-Repo M, Huhtala H, Miettinen A. Antineutrophil cytoplasmic antibodies in patients with early rheumatoid arthritis. Arthritis Rheum 2000;43: 1371-7.

51 Cambridge G, Williams M, Leaker B, Corbett M, Smith CR. Anti-myeloperoxidase antibodies in patients with rheumatoid arthritis: prevalence, clinical correlates, and IgG subclass. Ann Rheum Dis 1994;53:24-9.

52 Coremans IEM, Hagen EC, Daha MR, van der Woude FJ, van der Voort EAM, Kleijburg-van der Keur C, et al. Antilactoferrin antibodies in patients with rheumatoid arthritis lactoferrin antibodies in patients with rheumatoid arthritis
are associated with vasculitis. Arthritis Rheum 1992;35: are associatc

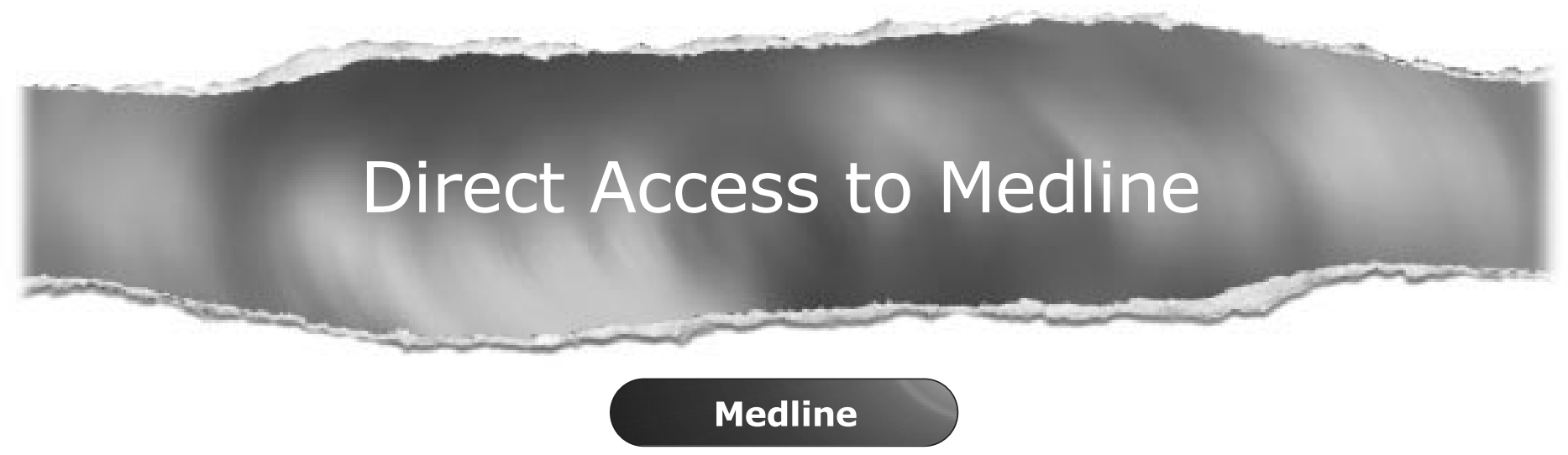

Link to Medline from the homepage and get straight into the National Library of Medicine's premier bibliographic database. Medline allows you to search across 9 million records of bibliographic citations and author abstracts from approximately 3,900 current biomedical journals.

www.annrheumdis.com 